\title{
Teaching Reformation of Ideological and Political Theory Courses Using PAD Class Mode in Colleges and Universities
}

\author{
Chen Ruifeng \\ School of Marxism, Shanghai Dianji University, Shanghai, China
}

Email address:

ruifeng20120417@126.com

To cite this article:

Chen Ruifeng. Teaching Reformation of Ideological and Political Theory Courses Using PAD Class Mode in Colleges and Universities. Engineering and Applied Sciences. Vol. 6, No. 1, 2021, pp. 26-32. doi: 10.11648/j.eas.20210601.13

Received: February 18, 2021; Accepted: March 16, 2021; Published: March 26, 2021

\begin{abstract}
This article will explain what is PAD (Presentation, Assimilation, Discussion) Class and its ideological and political theory courses in colleges and universities, through the three-part class teaching process, transforms the generative dynamic and autonomous reconstruction in the mutual "view" of theory and practice, so that college students can stand on the basis of the Marxist crowd and use Marxist methodology builds Marxist theory on the practice of the unity of knowledge, affection, will, action, and belief, and integrates the practice of unity of knowledge, affection, intention, action, and belief into Marxist theory. PAD class divides the class teaching process into three non-invertible processes: teaching, internalization and absorption, and discussion. The teaching, internalized absorption and discussion of the sub-class are quite different from the corresponding elements in the previous class teaching process, and the teaching, internalized absorption and discussion of the sub-class are all element innovations. The purpose of this paper is to draw the conclusion that each element on the class teaching process is the innovation and the teaching process as a whole, such integration innovation, through the dynamic generative independent construction, ideological and political theory course to realize the ideological and political education from passive to active, making the Marxist stand, methodology of Marxism and Marxism theory in college students' knowledge, affection, will, action, and belief, and integrates the practice of unity of knowledge, affection, intention, action, and belief into Marxist theory, is a new kind of teaching mode for the future, is worth us further practice and popularization.
\end{abstract}

Keywords: Ideological and Political Theory Course, Knowledge Sentiment will Activity Belief, Construct-produce, PAD Class

\section{Introduction}

Class is the main position and main channel of college students' ideological and political education. In March 2005, the Propaganda Department of the Central Committee of the Communist Party of China and the Ministry of Education issued the "Notice on the Implementation Plan for Further Strengthening and Improving the Ideological and Political Theory Courses in Colleges and Universities" (JiaoShezheng [2005] No. 9, referred to as the "05" Plan). Since the implementation of the "05 Plan", the class teaching process has been reformed, and the actual effect of ideological and political theory teaching has been improved, and the ideological and political education of college students has become a key and difficult task in the theoretical and practical circles. It has become a key task and difficult task in the theoretical and practical circles, and the "teaching model fever" has become inevitable. Some scholars pointed out: "There have been thousands of teaching models in our country so far." [1] Certainly, some teaching models are "blindly innovative, one-sided interpretation, exaggerated or fundamentally contradictory, and emphasize knowledge and skills." [2] On the whole, all these teaching models can be summarized into two categories: the traditional teaching model with "teaching" as the first, and the modern teaching model with "learning" as the first. [3] "Traditional model" and the modern model of "Learning before teaching". Some scholars believe that the traditional teaching model is the Kailov model, emphasizing the "teacher center", "classroom center", and "book center". "The cheese of Kailov pedagogy 
has become moldy." [4] To completely subvert, we must strive to establish an educational environment without the Kailov model. [5] The model of "learning before teaching" is represented by flipped classrooms. As of March 20, 2021, the paper "Research on Flipped Classroom Teaching Mode" has the highest citation rate, reaching 7354 times. [6] There are also scholars who insist that the traditional teaching model should not be "completely overthrown", and that various teaching methods should complement each other's advantages, have multiple simultaneous developments, and have multiple integrations. [7] At the same time, if the reform is too large, even though it has achieved greater The effect of the reform is no longer a reform of the teaching model, and this type of reform has become a generalized reform. [8] These studies and practices have indeed accumulated a certain amount of experience. On the basis of many studies and practices, certain experience has been accumulated and certain results have been formed. However, from a general inspection, the method and model of "a hundred flowers blossom and a hundred schools of thought contend" has not really "landed" the ideological and political education of college students. In 2015, the research team practiced a new class teaching mode-PAD Class, and achieved expected results, which are worthy of further practice and promotion.

\section{The Teaching Modes and Characteristics of PAD Class}

\subsection{What Is PAD Class}

The PAD Class is an original new teaching model proposed in 2014 by Professor Zhang Xuexin, a PhD in psychology from Princeton University and a PhD supervisor from the Department of Psychology of Fudan University, based on the principles of cognitive psychology. "[9] The above is clearly divided into three links: Presentation, Assimilation and Discussion, which are referred to as P, A, and $\mathrm{D}$ respectively. Therefore, the bisection classroom is also called the PAD class.

In the teaching session, the teacher does not exhaust the content of the textbooks, but only pays attention to the basic framework and difficult points of the unit course. Among them, the framework teaching is to tell the students the overall content and tasks of the unit course, to clarify the parts of the overall content and tasks, and the relationship between the parts, so that students can connect the various components in their thinking to form a About the overall structure of the overall content. The focus is on the goal and purpose of the unit course and the main links that clarify the goal and purpose. The difficulty is that the content of the course is not easy for college students to understand, which may be the key or non-key. Internalized absorption is the stage of autonomous learning. Students learn independently at their own pace and complete homework independently according to their own personal characteristics and specific circumstances. In the discussion session, after internalization and absorption, students return to the class to conduct group discussions, cooperative learning, and in-depth interaction with the class and teachers.

The core concept of PAD Class is to allocate about half of the time in class to teachers and discuss the other half to students, and separate the lecture and discussion time, so that students have a certain amount of time after class to independently arrange learning and carry out personalized internal absorption. Teachers set aside part of the time in class and give it to students to control and lead, forming a pattern of "division" between teachers and students. [10] Through this kind of "equivalence" reform, teachers and students have equal rights and obligations, and they can participate in "teaching-learning" activities more actively and effectively as subjects. Of course, this dichotomy in time is not strict, and can be adjusted according to actual conditions. At the same time, the teacher's lecture and the student's discussion are staggered in time, so that the students can learn independently and personally absorb, that is, this class discusses the content of the previous class. This kind of "separate discussion in class" is the fundamental difference between the dual and the traditional discussion in class, and it is also the key innovation of the dual class. [11] However, in the specific implementation process, confined to academic conditions, the dichotomy class also includes the form of class dichotomy and mixed dichotomy. Mixed dichotomy refers to "two-room dichotomy + one-room dichotomy".

After the PAD Class was proposed, in the spring semester of 2014, Mr. Zhang Xuexin made his first attempt in the second-year undergraduate "Psychological Experiment Design and Research Methods" class of the Fudan Department of Psychology, and the results were good. At present, the PAD Class model is widely recognized, disseminated and applied in higher education and general education, covering more than 100,000 students in thousands of courses in various disciplines and majors, and has been absorbed as a new teacher training course in Shanghai and a national university teacher network training The training courses of the center are also the "National Training Program" of the "National Training Program" (National Training Program for Primary and Secondary School Teachers) for primary and secondary school teachers.

\subsection{The Characteristics of PAD Class}

PAD Class through the three-part teaching process in class encourages students to realize generative and dynamic autonomous construction in the teaching process, and transforms the "preset-execute" traditional law-based class into a "preset-generate" class. [12]

\subsubsection{Emphasis on the Constructive and Generative Nature of Knowledge Learning}

After students receive new knowledge, whether it is taught by teachers, reading textbooks, or other forms, the knowledge is in a state of vagueness, and even conflicts with the students' original knowledge reserve. The content needs to go through a contact, mixing and running-in with the original content. After an ingestion process of selective 
digestion and absorption, it forms the construction. In this way, the student's original learning state can be changed and transferred, moving forward in the direction of the course goal, and this is generated. Even in the United States, seminar-style class still have a shortcoming: "Instant discussion", that is, after the teacher completes the lecture or course presentation, students are invited to discuss immediately without internalizing their independent learning. This is against the construction theory of psychology. In the past, people did not understand the theory, but did not pay attention to it. From the perspective of factors affecting human development, whether it is heredity, environment, or education, it is only under the action of the developing subject's own factors that they can play a role in mutual influence, rather than each always following a specific Angles have specific effects. This is the mechanical, static world view of modern philosophy, and the methodology of metaphysics.

\subsubsection{Emphasis on Construction-Generation Dynamics}

According to the laws of psychology, constructiongeneration is a phased and cumulative, a gradual process from quantitative change to qualitative change. One of the key points is that construction-generation is a dynamic circulation process of specific students' "input-output", requiring students' learning to be "input-output". No matter how many teachers prepare and no matter how deep their intentions are, they are all "input" rather than "output." In true self-study, students must construct "input"-generate "output", modify and perfect the "output", that is, reconstruct-generate "input" and then "output". For example, in a 90-minute class teaching process, for any student at any time, the result of the previous time is the construction condition of the next time, which determines the result of the next time, that is, the 44th The construction of the minute-the result of the generation determines the construction-the result of the 45th minute. In short, any factor that affects education is the process of generative and dynamic autonomous construction under the role of individual autonomy. The class teaching process is to build a platform, build an atmosphere, let students learn to "input-output" independently, and promote the dynamic progress of construction-generation.

\subsubsection{Emphasizes the Generative Dynamic Autonomous Construction Based on First Teaching"}

The PAD Class pays attention to the actual effect of students' learning in sub-classes, and emphasizes the time sequence of the three links of teaching, internalization and absorption and discussion. In short, emphasize "teaching first." "Teach first" is the opposite of "learn first". In implementing the class teaching system, the most fundamental psychological law is that students of different levels are arranged in different classes, and 6-year-old children and 10-year-old children cannot teach in the same class. There are inherent differences between students, and the link of "learning first" is added. Some students "learn first" and some students don't "learn first"; students who "learn first" have better abilities and some are more capable
Almost. "Learning first" objectively increases the individual differences among students. On the other hand, from the perspective of students, the "learning first" is halfway through, and what should I do if I hit a nail? Give up or continue? The students themselves do not have the ability to stop and move forward.

It is impossible for teachers to set the time to stop and continue in advance. In addition, the themes surrounding students "learn first" are also prepared by teachers. Students are unfamiliar and not proficient. Students are required to cover the contents prepared by teachers without "teaching first". This is unrealistic and impossible. Autonomous classes come from the United States, but American public education has never promoted autonomous classes.

\section{The Application and Practice of PAD Class in Ideological and Political Theory Courses in Colleges and Universities}

The application and practice of PAD Class in ideological and political theory courses in colleges and universities is to take the course "Introduction to the Basic Principles of Marxism" as an example.

In accordance with the principles of psychology, the ideological and political theory courses of colleges and universities, according to the law of learning and the training law of knowledge, affection, intention, behavior, and trust, introduce the internalization and absorption link of the split class, reconstruct the lecture link and the discussion link, and treat the existing The restructuring of the class teaching process in the form of a dichotomy of the ideological and political theory course. Take the "Introduction to the Basic Principles of Marxism" (hereinafter referred to as the "principle") course as an example for illustration.

\subsection{Ideological and Political Courses are Divided into PAD Class}

The "principle" PAD Class teaching content includes two parts: the overall framework, focus and difficulty of the unit course. Provide students with a self-constructed framework and backbone.

\subsubsection{Holistic Framework of Unit Courses}

Frame teaching is to tell students the overall content and tasks of the unit course, to clarify the overall content and the parts of the task and the relationship between the parts, so that students can connect the various components in their thinking to form an overall content The overall structure. Take "Marxism" as an example. "Marxism" is the object and task of the unit course, including four components: Marxism and the basic principles of Marxism, the establishment and development of Marxism, the distinctive features of Marxism, and the study and application of Marxism. The framework teaching is to tell the students about the four components of "Marxism" and the relationship between these 
four components, so that students can find the connection between these four components in their thinking, and then use these connections The four components are integrated and understood as a whole as a whole.

\subsubsection{The Focus and Difficulty of the Unit Course}

The focus of the unit course is the goal and purpose as a whole as a whole, as well as the main links that clarify the goal and purpose, how to establish a connection with the real society and the actual life of college students, and how college students practice in their own daily lives. Take "Marxism" as an example. "In a nutshell, Marxism was founded by Marx and Engels and developed by their successors. The scientific theoretical system aimed at criticizing capitalism, building socialism, and realizing communism is about the proletariat and human liberation. The science of science." [13] Therefore, the objective of the unit course is "Marxism is the science of the proletariat and the liberation of mankind". The science of this objective and purpose involves what the basic principles of Marxism and Marxism are, and what The purpose of the establishment and development, the main axis around the distinctive features, and how college students learn and apply Marxism. Then, the focus of the unit course is to "liberate" the definition of Marxism, the definition of the basic principles of Marxism, the creation and development of Marxism, the distinctive features of Marxism, and how college students learn and use Marxism.

The difficulty of the unit course is the course content that is not easy for college students to understand. Taking "Marxism" as an example, the difficulty is: how to understand the relationship between the four components of "Marxism"? How to understand that these four components constitute a total whole? How to understand "liberation"? How to understand "liberation" How to understand the relationship between "liberation" and the actual life of college students and the practice of Marxism?

\subsection{Ideological and Political Courses Are Internalized and Absorbed in PAD Class}

Internalization and absorption are the intermediate link of students' "generating and dynamic self-construction". It is students' self-learning and construction under the guidance and control of the teaching and textbook content, which plays a role of connecting the past and the next. Based on the education goal of the "principle" course, teachers link "what kind of person to train" and "how to train person" with specific unit courses, specific classes and students, from the perspective of the overall and systematic participation of courses and activities Starting from the start, implement the education goals into specific lessons, specific activities, and decompose it into the link of internalization and absorption, so that every specific internalization and absorption is a nutrient element of the overall training goal of students. In practice, the realization of this guiding task for teachers is implemented in the design and arrangement of homework content. According to different goals, there can be different operation methods as follows.

According to the knowledge goal, there are two operation methods. First, sort out the knowledge points. You can ask the students to sort out the "basic principles" involved in the unit courses based on the content of the textbook and the teacher's teaching. Second, understanding and thinking about knowledge points. Students are asked to digest and understand the knowledge points according to the content of the textbook and the teacher's teaching. Digestion and understanding are relatively open, with varying degrees of difficulty and gradients, and it is also challenging for students. Every student can have something to say according to their own mastery.

For ability goals, teachers can ask students to analyze the specific application of "basic principles" in combination with cases. Cases can be actual social life or personal life. And how to realize the migration of applications through the application of "basic principles" in the case, and practice the "basic principles" in their actual lives. Ability-based homework, the task objectives are as clear as possible, so that students can actually complete the possibility. Take "The Fundamental Law of the Development of Things" in Chapter One, Section Two of the "Principles" course as an example. First of all, in the overall direction of homework, it is positioned at development, which can be the development of college students, the development of non-college students, or the development of society. Then, understand the students' basic preferences, and focus on the development of a specific object when assigning homework. The larger ones, such as political development, economic development, cultural development, social development, ecological development, etc.; the smaller ones, such as the evolution history of bicycles, the evolution history of jacket styles, the evolution history of school bags, and so on. Secondly, the content of the case is also multifaceted. When assigning homework, you must also focus on a certain type of specific content. Otherwise, the students will not be able to grasp the case they need from the ever-changing world, nor can they The content they want to explore is captured from the multiple attributes of the case.

Regarding beliefs and values, first straighten out knowledge points, understand and think. For example, after studying "Communism", students are asked to combine their previous studies, and use socialist theory from fantasy to science, from science to practice, then to socialism with Chinese characteristics and the current Chinese dream as clues to talk about their own understanding. Secondly, on the basis of understanding, use cases to clarify the power of value choices and beliefs, and explore how to cultivate beliefs and value choices in real life, and practice Marxist world outlook, outlook on life and values. For comprehensive goals, you can assign homework like this: According to the content of the textbook and the teacher's explanation, connect yourself and the reality of the society, talk about your understanding, feelings and ideas, and think about how to practice it in your daily life. When setting up the homework, it is necessary to not only according to the 
content of the unit course itself, but also according to what content has been assigned in the past, and also consider the internal connection of the "basic principle" itself, and try to ensure that every homework is a unit Part of the "three-point content" of the course, which helps to effectively derive the topic of the next unit course.

\subsection{Ideological and Political Class Is Divided into PAD Class Discussion}

The "principle" course is divided into class discussion, which is the final link of "generating dynamic autonomous construction". The task of autonomous construction required by students is: integrating theory with practice. That is, to further integrate the "fundamental principles" into the reality of broader economic life, political life, cultural life, social life and ecological life, examine the way in which the "fundamental principles" operate and exist in real life, and learn to consciously use " "Basic Principles" observe and analyze multiple and diverse material and spiritual phenomena. By integrating "Basic Principles" into one's daily life, we will strengthen our belief in "Basic Principles" and consciously practice "Basic Principles". The completion of this task is mainly achieved through a large number of real cases brought into the discussion site by the students and the exchange of cases and "basic principles". Through the intermediary of internalization and absorption, the students have understood and thought about the "basic principles" in combination with actual cases. Therefore, in the discussion session, the students have brought their own cases and their theoretical results into the discussion. Enter the discussion site. In this way, through the integration of "basic principles" into specific life reality, in the collision of thinking, students can more deeply understand "a correct understanding often needs to go through from material to spirit, from spirit to material, that is, from practice to Cognition can only be accomplished by recognizing and practicing such many times of repetition", and its goal and purpose is to rely on the interests of the broad masses of the people, obtain truthful knowledge, combine theory with practice, and unify truth and value. Starting from lectures, through internalization and absorption, and then to discussion, with repeated "realistic architecture", the logical structure of "basic principles" has been "assimilated" with the mental structure of college students.

On the basis of strengthening "assimilation", students further strengthened their world outlook, outlook on life and values. Another task of the discussion is to promote "assimilation" to "Hue". Piaget pointed out: The recognizer assimilates objects into the structure of his actions (or his calculations), and at the same time adjusts these structures (by dividing them) to conform to the unforeseen encounters he encounters in reality. Aspect." [14] Conform to the unforeseen aspects he encountered in reality" is that college students give "basic principles" practical power to transform from spiritual existence to material existence, showing strong material power. This is the final self-construction of college students, But it is also a significant and even the most significant step.

\section{The Significance of Applying the PAD Class in Colleges and Universities}

Ideological and political theory courses are divided into classes, through the three-part class teaching process, in the theory and practice The mutual "view" enables college students to base themselves on the Marxist mass standpoint, use Marxist methodology, and build Marxist theory on the mass practice of the unity of knowledge, affection, will, behavior, and faith, and then learn about themselves. The practice of unity of affection, will, behavior, and faith has been integrated into Marxist theory, making Marxist theory "landed" in the ideological and political education of college students.

First of all, the ideological and political theory of PAD Class is divided into classes centered on the self-construction of students. By decomposing the unit course tasks into three parts, different tasks correspond to different stages of the class teaching process, which not only controls the course objectives and scope of tasks, and enables students to construct themselves It becomes possible; it can also restore the student's dominant status, reduce the burden on teachers, encourage teachers and students to divide the class, and become the dual subject of the class teaching process. Class teaching thus crosses the threshold from passive learning to active learning, and realizes students' self-construction; Moreover, the cutting of the three stages of the teaching process has effectively gradually expanded the scope of students' self-construction. When teachers are giving lectures on frameworks and difficult points, students receive knowledge and feel the emotions, will and beliefs conveyed by the teacher's voice and posture, and at the same time digest and process the "input" to form their own course content framework and key points, Through the "construction-generation" internalization of the core goals of the curriculum that are external to oneself. On this basis, the internalization and absorption stage, independent study and independent homework, enable college students to turn Marxist theory into daily practice, so that the theory can cross the self-enclosed threshold and radiate to the complex and varied life reality. Gradually expand the coverage of the core objectives of the curriculum to make it "constructgenerate" branches and leaves. Then through group discussion, self-construction expands into group construction, and then through the whole class communication, group construction develops into class construction, and finally, through the teacher's induction and summary, each student supplements his own "constructiongeneration" work Modify and complete the learning and construction tasks of the unit course.

Secondly, the ideological and political theory of PAD Class is divided into classes to unify theory and practice, and through the three stages of the class teaching process, continue to enrich the construction and highlight the practice 
of theory. Especially in the discussion stage, through group communication with each student's practice, and then from group communication to the whole class communication, the practice encountered by the students shows a geometric multiple expansion in the vertical and horizontal directions, so that the students gradually understand Marxist theory is embedded in mass practice. Theory is actually the selfexpression of mass practice, discovered and condensed by the "thinking mind". Since practice itself is infinite, theory unfolds in practice again and returns to practice. Theory is the theory of practice, and practice is the practice of theory. In this way, the students not only clarified the connotation of the theory, but also can apply the theory to practice, and apply their knowledge and ability to practice; It also made it clear that without mass practice, there would be no Marxist theory, the practical application of theories and the pursuit and maintenance of mass interests, so as to learn to learn, do things and live in the interests of the masses. This is the mass position of Marxism.

Third, PAD Class with mass practice to clarify the theory returns to the practical essence of Marxism, and base the epistemology on the ontology and methodology, so that students try to find relevant practices in the historical process when they understand Marxist theory. Discovering theories in the continuity of history, discovering theories in the process of history, discovering theories in the development of the negation of the historical negation, and letting one's own thinking methods base on a great sense of history, reality and times. Therefore, theory is the inherent and inherent nature of practice that is historically linked. Using this method to explore and understand Marxist theory is the methodology of Marxism.

Fourth, the PAD Class are based on the Marxist mass standpoint, using Marxist methodology and mass practice throughout Marxist theory. And any mass practice must be purposeful, and unite the inner expectations and emotional appeals of the masses. In practice, the masses use their own goals as the basis to understand and transform nature, society, and themselves, seek the unity of truth and value in practice, and strengthen their will and belief in the unity of truth and value. Therefore, practice is the practice of the unity of knowledge, affection, intention, action, and faith. In the parallel class, Marxist theory is based on the practice of unity of knowledge, affection, intention, action, and faith, so that college students understand that "history is nothing but The activities of people pursuing their own goals are only" [15]. I am also a member of the creation of history, and my own practice is also the practice of creating history, so as to transform the external practice of the unity of knowledge, affection, intention, action, and faith into internal practice, and the theory of external connection into the theory of internal connection. Integrate one's own study, work, and life practice into the practice of the masses, link one's knowledge, feelings, intentions, behavior, and belief with Marxist theory, so that Marxist theory "landed" in the ideological and political education of college students.

\section{Conclusion}

In short, firstly, the PAD class divides the class teaching process into three non-invertible processes: teaching, internalization and absorption, and discussion. Here, it must be clear that the three processes are the whole of the classroom teaching process, and the order cannot be reversed, otherwise, it is not the class, because this is the innovation of the class in the class teaching process.

Secondly, the teaching, internalized absorption and discussion of the sub-class are quite different from the corresponding elements in the previous class teaching process, and the teaching, internalized absorption and discussion of the sub-class are all element innovations. Each element on the class teaching process is the innovation and the teaching process as a whole, such integration innovation, through the dynamic generative independent construction, ideological and political theory course to realize the ideological and political education from passive to active, making the Marxist stand, methodology of Marxism and Marxism theory in college students' knowledge, affection, will, action, and belief, and integrates the practice of unity of knowledge, affection, intention, action, and belief into Marxist theory, is a new kind of teaching mode for the future, is worth us further practice and popularization.

\section{References}

[1] Hu Jifei, Gu Lixin. On the path and method of teaching mode inheritance and innovation [J]. Curriculum Textbook Teaching Method, 2015 (11): 37.

[2] Wan Wei. The status quo, problems and development trends of teaching mode research in the past thirty years $[\mathrm{J}]$. Chinese Journal of Education, 2015 (1): 60.

[3] Huang Wei, Jiao Qianglei. Based on the teaching relationship Classroom teaching model reform $[\mathrm{J}]$. Curriculum Textbook Teaching Method, 2016 (3): 71.

[4] [4] Zhong Qiquan. Moldy Cheese [J]. Global Education Outlook, 2004 (10): 3-17.

[5] Chen Zhigang, Zhang Ziping. The problem of curriculum reform: the legacy of the Kailov teaching model [J]. Global Education Outlook, 2013 (6): 29.

[6] China Knowledge Network [DB/OL]. https:// www.cnki.net/, (2021.3.20)[2021-3-20]

[7] Wang Cesan. On Guiding Self-study Experiments-A Comment on the Reform of "Learning First and Teaching Later" [J]. Journal of Shanxi University (Philosophy and Society) Science Edition), 2016 (3): 88-90.

[8] Zheng Yufei. On the limits of teaching model reform [J]. Educational Science, 2018 (3): 27. Zhang Xuexin. PAD Class. [N]. Educational Digest Weekly, 2016-03-02 (1).

[9] Zhang Xuexin. PAD Class. [N]. Educational Digest Weekly, 2016-03-02 (1)

[10] Zhang Xuexin. PAD Class: a new exploration of college class teaching reform [J]. Fudan Education Forum, 2014 (5): 5-6. 
[11] Zhang Xuexin. PAD Classs: a new teaching method [J]. Special Issue on Teaching and Learning of Fudan University, 2014 (2): 1-2.

[12] Chen Ruifeng. PAD CLass: exploration of generative class teaching mode [J]. Shanghai Educational Research, 2016 (3): $71-74$.
[13] The book writing group. Introduction to the basic principles of Marxism [M]. Beijing: Higher Education Press, 2015: 2.

[14] Piaget. Selection of Piaget Educational Works [M]. Version 2. Lu Jun, translated. Beijing: People's Education Press, 2015: 2.

[15] Marx, Engels. Collected Works of Marx and Engels: Volume 1 [M]. Beijing: People's Publishing House, 2009: 295. 